\title{
A decade to study deep-sea life
}

\author{
The United Nations Decade of Ocean Science for Sustainable Development presents an exceptional opportunity \\ to effect positive change in ocean use. We outline what is required of the deep-sea research community to achieve
} these ambitious objectives.

\begin{abstract}
Kerry L. Howell, Ana Hilário, A. Louise Allcock, David Bailey, Maria Baker, Malcolm R. Clark, Ana Colaço, Jon Copley, Erik E. Cordes, Roberto Danovaro, Awantha Dissanayake, Elva Escobar, Patricia Esquete, Austin J. Gallagher, Andrew R. Gates, Sylvie M. Gaudron, Christopher R. German, Kristina M. Gjerde, Nicholas D. Higgs, Nadine Le Bris, Lisa A. Levin, Elisabetta Manea, Craig McClain, Lenaick Menot, Nelia C. Mestre, Anna Metaxas, Rosanna Milligan, Agnes W. N. Muthumbi, Bhavani E. Narayanaswamy, Sofia P. Ramalho, Eva Ramirez-Llodra, Laura M. Robson, Alex D. Rogers, Javier Sellanes, Julia D. Sigwart, Kerry Sink, Paul V. R. Snelgrove, Paris V. Stefanoudis, Paulo Y. Sumida, Michelle L. Taylor, Andrew R. Thurber, Rui Vieira, Hiromi K. Watanabe, Lucy C. Woodall and Joana R. Xavier
\end{abstract}

$\mathrm{T}$ he health of the global ocean, on which society depends, is in decline. The importance of sustainable use to ocean health has long been recognized ${ }^{1}$, yet the United Nations (UN) First World Ocean Assessment ${ }^{2}$ from 2017 highlighted increasing ocean pressures from accelerated expansion of human activities, including climate change. These pressures affect all ocean regions, from the coast to the deep $\mathrm{sea}^{3}$. In response to this concern, and to align with several international policy commitments, the UN General Assembly proclaimed 2021-2030 the Decade of Ocean Science for Sustainable Development ${ }^{4}$.

The roadmap for this Ocean Decade recognizes the deep sea as a frontier of science and discovery, and calls for research to advance understanding of deep-sea ecosystems, their functions, vulnerabilities and services to society. Published in March 2020, the draft implementation plan for the Ocean Decade guides the design and implementation of 'Actions' that underpin the desired move from 'the ocean we have' to 'the ocean we want' (Fig. 1). The draft plan calls on the scientific community to develop Actions, at programme, project, activity or contribution levels, to help deliver on four key objectives: (1) increase capacity to generate, understand, manage and use ocean knowledge; (2) identify and generate required ocean data, information and knowledge; (3) build comprehensive understanding of the ocean and its governance systems; and (4) increase the use of ocean knowledge.

The deep-sea biology community has responded to this call through working groups of the Deep-Ocean Stewardship Initiative (DOSI) and the Scientific Committee on Oceanic Research. In keeping with the Ocean Decade's focus on fair and equitable partnerships, these groups include experts from developed and developing nations, representing diverse ethnic backgrounds, different genders and career stages. Together, these groups have considered the research needs associated with each of the four objectives in a deep-sea biology context. Here, members of both working groups present recommendations under each objective to inform the development of deep-sea-focused Ocean Decade Actions.

\section{Objective 1: Capacity development}

There is unequal capacity to conduct deep-ocean science among nations; countries with developing economies face substantial barriers to participating in deep-sea research, including access to technological capability and infrastructure, and to specific expertise. Thus, although more than $70 \%$ of countries' Exclusive Economic Zones (EEZs) contain deep-sea environments, most deep-sea research is conducted by only a small subset of economically developed nations. Consequently, the least-studied parts of the deep sea are within the EEZs of least economically developed countries and large ocean states (also known as small island developing states). Availability of samples, data and overall knowledge of deep-sea ecosystems reflect these biases. Even where such nations can participate, barriers to publishing in international journals often result in country-specific publications only.

Deep-sea-focused Ocean Decade Actions must therefore strive to expand capacity development by coordinating efforts across deep-sea research projects and regions to provide sea-going opportunities for researchers from nations that have limited access to large-scale infrastructures. All Actions should commit to co-developing and co-producing transregional research at an early stage of design, partnering with local collaborators. The planned research should value and build upon local and/ or indigenous knowledge systems. This approach will bring different perspectives and approaches to deep-sea research ${ }^{5}$, and encourage a new generation of deep-sea scientists and educators by highlighting diverse role models and opportunities. All Actions should facilitate open access to marine scientific research outputs, marine technologies and ocean knowledge, using best practices. These should follow both the principles of being findable, accessible, interoperable and reusable (FAIR) and the principles of collective benefit, authority to control, responsibility and ethics (CARE). Existing and planned UN-supported initiatives, such as the Ocean Biodiversity Information System (OBIS), and the International Oceanographic Data and Information Exchange should be employed. All Actions should commit to sharing specimens, including whole animals, tissue, barcoding and environmental DNA samples, and invest in the deposition of specimens in established and regionally relevant institutions that have recognized charters to support permanent storage and care of archived specimens. We recommend open access publication of research and data where possible.

\section{Objective 2: Generate ocean data} Physical and biogeochemical observing programmes in the deep ocean have expanded recently at local, regional and global scales. However, sustained biological 


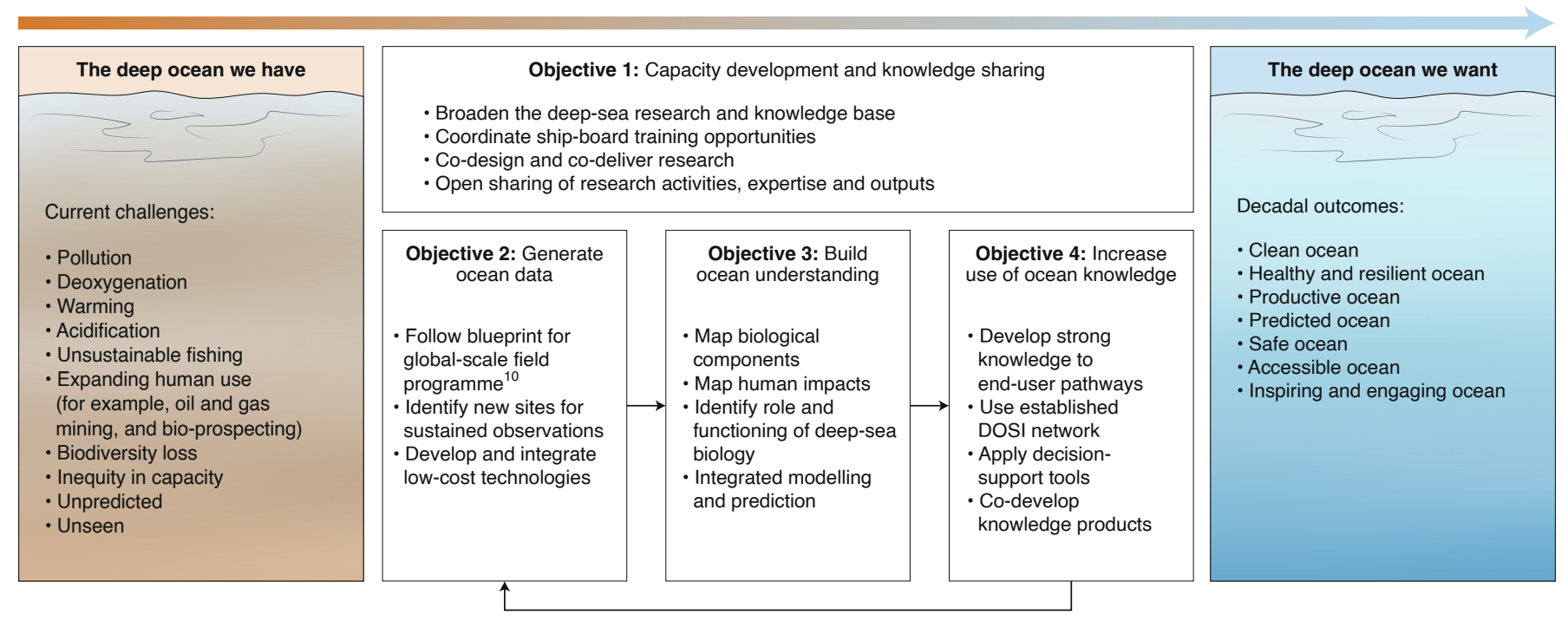

Fig. 1 | Steps towards a sustainable deep ocean. The UN's Ocean Decade aims to understand the ocean we have, and drive progress to the ocean we want, via four objectives. We have assessed the Ocean Decade's objectives through a lens of deep-sea biology, and provide recommendations to support the development of Actions to achieve these objectives.

observing programmes have lagged behind, and only a handful of long-term study sites are in operation ${ }^{6}$. Spatial bias occurs in biological ocean observations, with under-sampling of equatorial and polar regions, and of the Southern Hemisphere more generally ${ }^{7}$. Globally, sampling effort decreases with depth ${ }^{8}$. Although recent technological advances allow every part of the deep ocean to be accessed, the capacity to deploy assets remains restricted worldwide because of the high cost of suitable vessels and limited available infrastructure.

A coordinated international effort is needed to expand deep-sea biological observations and sampling in all ocean basins, specifically focusing on underexplored regions 9 . A blueprint for a global-scale field programme using standardized methods, stratified by latitude, biogeographic region and depth, among other key variables, has recently been prepared ${ }^{10}$ that addresses this issue. We recommend that Ocean Decade field-survey Actions follow this blueprint to support completion of a global sampling 'jigsaw puzzle, designed to deliver comparable scientific knowledge in all ocean basins. The blueprint also highlights the need to identify biogeographically representative sites to initiate a globally comprehensive site network for sustained observations.

Expanding both spatial and temporal biological observations in the deep ocean will require small and low-cost technologies to enable broader participation ${ }^{11,12}$. Ocean Decade Actions should build on existing efforts within our deep-sea research community to develop and apply such technologies under a standardized framework.

\section{Objective 3: Build ocean understanding} Despite increased research efforts in recent years, fundamental biological, ecological and taxonomic information for much of the deep ocean is still urgently needed to improve the predictions, forecasting and modelling that inform decision-making, policy, management and innovation. Accurate prediction of how biodiversity will respond to climate change and other anthropogenic pressures requires data on existing species, their biotic and abiotic tolerances and interactions, in addition to better characterization of climate stressors at deep-sea habitat-representative spatial and temporal scales. Effective ocean management and sustainable use also critically depend on understanding deep-sea connectivity — linkages among deep-sea ecosystems, communities, species and populations. A clearer understanding of the role of the deep ocean in the provision of ecosystem services at regional and global scales is also needed.

Ocean Decade Actions must expand knowledge of offshore and deep-sea ecosystems and associated anthropogenic impacts. Mapping the biological components of the deep sea, describing what we have, where and how it lives is essential to achieving this objective. We recommend Actions look to map ecosystem services delivered by the deep seas, and flows of benefits to society. Evaluation of current baselines and human impacts across temporal and spatial scales, following standardized methodologies and a dynamic stratified design is needed. Through targeted sampling and experimentation, Actions should identify the role and functioning of deep-sea biology, including those systems essential to ocean and human health. The acquired information can then be used to map and quantify human impacts in the deep sea and assess the feasibility of future restoration action $s^{13}$. Collectively, this knowledge will facilitate improved modelling and predictive capacity to deliver relevant and timely societal services that can inform sustainable ocean management. These results can feed into UN processes, as well as regional and national management bodies.

\section{Objective 4: Increase use of ocean knowledge}

Decision-making processes to ensure sustainable use of the marine environment require synthesis of multiple streams of knowledge to reach evidence-based choices. Although researchers have developed decision-support tools that have been applied to marine spatial planning (reviewed in ref. ${ }^{14}$ ), few have been applied specifically to the deep sea ${ }^{15}$.

Ocean Decade Actions should strive to inform ecosystem-based management to support global, regional and local decision-making in the deep ocean. Working with the UN, and relevant regional and national bodies, Actions should further 
develop and trial decision-support tools and scenario-based systems for informed decision-making and adaptive management at local to global scales. Actions should foster the development of effective 'knowledge to end-user' pathways, building on already successful community initiatives, for example DOSI.

\section{A ten-year research programme}

The Ocean Decade begins on 1 January 2021. Our recommendations provide a resource for deep-sea biologists seeking to engage with the Ocean Decade through developing their own Actions. However, they also provide the basis for the development of a deep-sea-focused programme-level Action designed to coordinate and monitor deep-sea research effort. Such a programme could build on previous global decadal efforts, most recently the Census of Marine Life (CoML) (2001-2010). The CoML brought together more than 2,700 researchers from around the world to evaluate the diversity, distribution and abundance of life in the global ocean. Of the 17 major projects under the CoML, five specifically focused on deep-sea ecosystems, and these provide key reference points. A new programme, designed around the Ocean Decade objectives, would be more likely to generate the level of knowledge advance needed to inform and support high-level policy processes, including the Sustainable Development Goals and Aichi 2030 Targets, than individual project-level Actions could achieve in isolation. We argue that a ten-year programme to enact our recommendations is essential if we are to move to a more sustainable future for our deep ocean. This Ocean Decade is the time to act, and we must all seize the opportunity.

Kerry L. Howell (D) 1凶, Ana Hilário (D)2, A.LouiseAllcock (D) ${ }^{3}$,DavidBailey (iD ${ }^{4}$, MariaBaker ${ }^{5}$, Malcolm R. Clark ${ }^{6}$, Ana Colaço ${ }^{7}$, Jon Copley ${ }^{5}$, Erik E. Cordes (D) 8 , Roberto Danovaro 9,10, Awantha Dissanayake ${ }^{11}$, Elva Escobar ${ }^{12}$, Patricia Esquete (iD) ${ }^{2}$, Austin J. Gallagher ${ }^{13}$, Andrew R. Gates ${ }^{14}$, Sylvie M. Gaudron ${ }^{15,16}$, Christopher R. German ${ }^{17}$, Kristina M. Gjerde ${ }^{18}$, Nicholas D. Higgs ${ }^{19}$, Nadine Le Bris ${ }^{20}$, Lisa A. Levin (1D21, Elisabetta Manea22, Craig McClain ${ }^{23}$, Lenaick Menot (D) 24, Nelia C. Mestre (iD) ${ }^{25}$ Anna Metaxas ${ }^{26}$,
Rosanna Milligan ${ }^{27}$, Agnes W. N. Muthumbi ${ }^{28}$, Bhavani E. Narayanaswamy ${ }^{29}$,

Sofia P. Ramalho², Eva Ramirez-Llodra ${ }^{30,31}$, Laura M. Robson ${ }^{32}$, Alex D. Rogers ${ }^{31}$, Javier Sellanes ${ }^{33}$, Julia D. Sigwart (D) 34 , Kerry Sink ${ }^{35}$, Paul V. R. Snelgrove (iD) 36 , Paris V. Stefanoudis (D) 37,38,

Paulo Y. Sumida (iD) ${ }^{39}$, Michelle L. Taylor ${ }^{40}$, Andrew R. Thurber (D) ${ }^{41}$, Rui Vieira (D) ${ }^{42}$, Hiromi K. Watanabe ${ }^{43}$, Lucy C. Woodall ${ }^{37,38}$ and Joana R. Xavier ${ }^{44,45}$

${ }^{1}$ School of Biological and Marine Sciences, Plymouth University, Plymouth, UK. ${ }^{2}$ CESAM \& Biology Department, University of Aveiro, Aveiro, Portugal. ${ }^{3}$ Ryan Institute and School of Natural Sciences, National University of Ireland Galway, Galway, Ireland. ${ }^{4}$ Institute for Biodiversity, Animal Health and Comparative Medicine, University of Glasgow, Glasgow, UK. ${ }^{5}$ School of Ocean and Earth Sciences, University of Southampton Waterfront Campus, National Oceanography Centre, Southampton, UK. ${ }^{6}$ National Institute of Water and Atmospheric Research, Wellington, New Zealand. ${ }^{7}$ Instituto do Mar, and Instituto de Investigação em Ciências do Mar - Okeanos da Universidade dos Açores, Horta, Portugal. ${ }^{8}$ Department of Biology, Temple University, Philadelphia, PA, USA. ${ }^{9}$ Department of Life and Environmental Sciences, Polytechnic University of Marche, Ancona, Italy. ${ }^{10}$ Stazione Zoologica Anton Dohrn, Naples, Italy. ${ }^{11}$ University of Gibraltar, Gibraltar, Gibraltar. ${ }^{12}$ Instituto de Ciencias del Mar y Limnología Universidad, Nacional Autónoma de México, Ciudad Universitaria, México, México. ${ }^{13}$ Beneath the Waves, Herndon, VA, USA. ${ }^{14}$ National Oceanography Centre, Southampton, UK. ${ }^{15} \mathrm{UMR}$ 8187 Laboratoire d'Océanologie et de Géosciences, Université de Lille, ULCO, CNRS, Lille, France. ${ }^{16}$ Sorbonne Université, UFR 927, Paris, France. ${ }^{17}$ Department of Geology \& Geophysics, Woods Hole Oceanographic Institution, Woods Hole, MA, USA. ${ }^{18}$ IUCN Global Marine and Polar Programme, Cambridge, MA, USA. ${ }^{19}$ Cape Eleuthera Institute,

$\square \quad$ Rock Sound, Eleuthera, Bahamas. ${ }^{20}$ Sorbonne University, Banyuls Oceanological Observatory, Paris, France. ${ }^{21}$ Center for Marine Biodiversity and Conservation, Scripps Institution of Oceanography, University of California, San Diego, La Jolla, CA, USA. ${ }^{22}$ Institute of Marine Sciences, National Research Council, ISMAR-CNR, Venice, Italy. ${ }^{23}$ Louisiana Universities Marine Consortium, Chauvin, LA, USA. ${ }^{24}$ Ifremer, Plouzané, France. ${ }^{25}$ CIMA - Centro de Investigação Marinha e Ambiental, Universidade do Algarve, Faro, Portugal. ${ }^{26}$ Department of Oceanography, Dalhousie University, Halifax, Nova Scotia, Canada. ${ }^{27}$ Halmos College of Natural Sciences and Oceanography, Nova
Southeastern University, Dania Beach, FL, USA. ${ }^{28}$ School of Biological Sciences, University of Nairobi, Nairobi, Kenya. ${ }^{29}$ The Scottish Association for Marine Science, Oban, UK. ${ }^{30}$ Norwegian Institute for Water Research, Oslo, Norway. ${ }^{31}$ REV Ocean, Lysaker, Norway. ${ }^{32}$ The Joint Nature Conservation Committee, Peterborough, UK. ${ }^{33}$ Department of Marine Biology \& Millennium Nucleus ESMOI, Universidad Católica del Norte, Coquimbo, Chile. ${ }^{34}$ Senckenberg Research Institute, Frankfurt, Germany. ${ }^{35}$ Centre for Biodiversity Conservation, South African National Biodiversity Institute, Kirstenbosch, Newlands, South Africa. ${ }^{36}$ Department of Ocean Sciences and Biology Department, Memorial University of Newfoundland, St. John's, Newfoundland and Labrador, Canada. ${ }^{37}$ Department of Zoology, University of Oxford, Oxford, UK. ${ }^{38}$ Nekton Foundation, Begbroke, UK. ${ }^{39}$ Instituto Oceanográfico, Universidade de São Paulo, São Paulo, Brazil. ${ }^{40}$ School of Life Science, University of Essex, Colchester, UK. ${ }^{41}$ College of Earth, Ocean, and Atmospheric Sciences and Department of Microbiology, College of Science, Oregon State University, Corvallis, OR, USA. ${ }^{42}$ Centre for Environment, Fisheries \& Aquaculture Science, Lowestoft Laboratory, Lowestoft, Suffolk, UK. ${ }^{43}$ X-STAR, Japan Agency for Marine-Earth Science and Technology (JAMSTEC), Yokosuka, Japan. ${ }^{44}$ Interdisciplinary Centre of Marine and Environmental Research (CIIMAR), University of Porto, Matosinhos, Portugal. ${ }^{45}$ Department of Biological Sciences and K.G. Jebsen Centre for Deep-Sea Research, University of Bergen, Bergen, Norway.

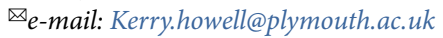

Published online: 25 November 2020 https://doi.org/10.1038/s41559-020-01352-5

\section{References}

1. Costanza, R. \& Mageau, M. Aquat. Ecol. 33, 105-115 (1999).

2. United Nations The First Global Integrated Marine Assessment: World Ocean Assessment I (Cambridge Univ. Press, 2017).

3. Levin, L. A. et al. Glob. Change Biol. 26, 4664-4678 (2020).

4. Ryabinin, V. et al. Front. Mar. Sci. 6, 470 (2019).

5. Illsley-Kemp, F., Barker, S. J., Smith, B. \& Wilson, C. J. N. Eos 101, https://doi.org/10.1029/2020EO140955 (2020).

6. Levin, L. A. et al. Front. Mar. Sci. 6, 241 (2019).

7. Menegotto, A. \& Rangel, T. F. Nat. Commun. 9, 4713 (2018).

8. Webb, T. J., Vanden Berghe, E. \& O'Dor, R. PLoS ONE 5, e10223 (2010).

9. Danovaro, R. et al. Nat. Ecol. Evol. 4, 181-192 (2020).

10. Howell, K. L. et al. Front. Mar. Sci. https://doi.org/10.3389/ fmars.2020.584861 (in the press).

11. Hand, K. P. \& German, C. R. Nat. Geosci. 11, 2-4 (2018).

12. Phillips, B. T. et al. Deep Sea Res. I 153, 103136 (2019).

13. Barbier, E. B. et al. Nature 505, 475-477 (2014).

14. Pınarbaşı, K. et al. Mar. Policy 83, 83-91 (2017).

15. Evans, J. L., Peckett, F. \& Howell, K. L. ICES J. Mar. Sci. 72, 1483-1497 (2015)

Competing interests

The authors declare no competing interests. 